\section{Additions to wood decaying fungi of India}

\section{C.K. Tiwari ${ }^{1}$, Jagrati Parihar $^{2}$ \& R.K. Verma ${ }^{3}$}

1,2,3 Forest Pathology Division, Tropical Forest Research Institute, Jabalpur, Madhya Pradesh 482021, India Email: ${ }^{1}$ ck_scientist@yahoo.com, ${ }^{2}$ jags.parihar@gmail.com, ${ }^{3}$ rkverma28@rediffmail.com (corresponding author)

Wood decaying fungi are the important elements of forest ecosystems, as they take care of the decomposition of coarse woody debris (fallen trunks, branches, stumps, etc). Among them, Polypores (Basidiomycota) constitute the major group. They are intensively studied and systematically documented in Europe and North America (Donk 1962; Burdsall 1985; Gilbertson \& Ryvarden 1987; Hjortstam \& Ryvarden 1990; Ryvarden \& Gilbertson 1994). Several resupinate species have been published from different parts of the world (Jülich 1976; Hjorstam \& Ryvarden 1982; Roy \& De 1996; Hattori \& Lee 1999; Dai 2000; Lee et al. 2004). Moreover, Parmasto (1986) has published species from subtropical and tropical Pacific Asia. Many researchers studied wood decaying resupinate fungi in India (Bose 1938; Banerjee 1947; Bagchee \& Bakshi 1951; Bakshi 1971; Thind \& Dhanda 1980; Roy \& De 1996). In central India, these fungi have been studied from Sagar, Harda, Mandla and Jhabua (Saksena \& Vyas 1964; Verma et al. 2008). The present paper gives an account of three new records of resupinate wood decaying fungi from Raipur, Jagdalpur, and Kanker districts of Chhattisgarh.

Date of publication (online): 26 June 2010

Date of publication (print): 26 June 2010

ISSN 0974-7907 (online) | 0974-7893 (print)

Editor: V.B. Hosagoudar

\section{Manuscript details:}

Ms \# 02214

Received 23 May 2009

Final received 10 September 2009

Finally accepted 05 May 2010

Citation: Tiwari, C.K., J. Parihar \& R.K. Verma (2010). Additions to wood decaying fungi of India. Journal of Threatened Taxa 2(6): 970-973.

Copyright: @ C C.K. Tiwari, Jagrati Parihar \& R.K. Verma 2010. Creative Commons Attribution 3.0 Unported License. JoTT allows unrestricted use of this article in any medium for non-profit purposes, reproduction and distribution by providing adequate credit to the authors and the source of publication

Acknowledgement: The authors would like to thank Dr. A.K. Mandal, Director, TFRI, for providing necessary facilities and Indian Council of Forestry Research and Education for financial support under Project I.D. No. 130/TFRI/2008/Path-2(14).

\section{OPEN ACCESS | FREE DOWNLOAD (C) (i) @}

\section{Materials and Methods}

The fruit-bodies of resupinate wood decaying fungi were collected during rainy season i.e. July to September 2008 from Chhattisgarh state of central India, geographically ranging from

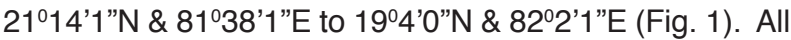
the macroscopic and habitat characteristics were noted in situ. Detailed microscopic examinations were made and were identified with the help of the following literature (Rattan 1977; Ryvarden \& Johansen 1980; Natrajan \& Kolandavelu 1998; Lim et al. 2001; Zmitrovich et al. 2006). Xanthochroic reaction was determined by placing a small piece of material in $10 \% \mathrm{KOH}$ solution. Free hand sections were made. The cyanophility was observed in cotton blue mounted in lactophenol and amylodity of structures in Melzer's reagent. The photographs were taken with a Nikon F601 SLR Camera, macroscopic and microscopic characters were studied under the stereozoom Leica, Model Wild M3Z and Advanced Research Microscope, Leica, Model Leitz DMRB (Germany) and camera lucida drawing were also prepared with the help of Triumph trinocular research microscope. The specimens are deposited in the Mycology Herbarium of the Forest Pathology Division at Tropical Forest Research Institute, Jabalpur (TF). The records are new to India since the following authors do not mention them, Butler \& Bisby (1954), Tandon \& Chandra (1964), Bilgrami et al. (1979, 1981, 1991), Sarbhoy et al. (1975, 1986, 1996), Bhide et al. (1987) and Jamaluddin et al. (2004).

\section{Taxonomy}

Australohydnum dregeanum (Berk.) Hjortstam \& Ryvarden Syn. Fung. (Oslo) 4: 61 (1990) (Fig. 2, Image 1)

\section{Material examined}

2.x.2008, on stored logs of Anogeissus latifolia Wall., Kanker, Chhattisgarh, 2016'18”'N \& 8129'35"E, coll. C.K. Tiwari, Jagrati Parihar \& R.K. Verma, Reg.no. TF 1140.

This fungus causes white fibrous rot.

Lopharia dregeana (Berk.) P.H.B. Talbot. Bothalia 6:57 (1951)

Basidiome: annual, resupinate or effuso-reflexed, imbricate, $2-7 \times 1-5 \times 0.2-0.5 \mathrm{~cm}(\mathrm{~L} \times \mathrm{B} \times \mathrm{H})$. Pileus: hirsute, hispid, dark brown, zonate, no xanthochroic reaction with $\mathrm{KOH}$. Hymenophore: merulioid, daedaloid to reticulateporose, brown. Context: brown, 2-4 mm thick. Hyphal system: monomitic, generative hyphae septate, with or without clamps, thin- to thick-walled with a narrow lumen, 3.5-7.5 $\mu \mathrm{m}$ wide, amyloid. Cystidia: heavily encrusted lamprocystidia both of tramal and hymenial origin, 20-25 x $5 \mu \mathrm{m}$. Basidia: long clavate, basally simple septate. Basidiospores: 2.5-3.0 $\mu \mathrm{m}$, subglobose, hyaline.

Macroscopically, this species resembles Punctularia 


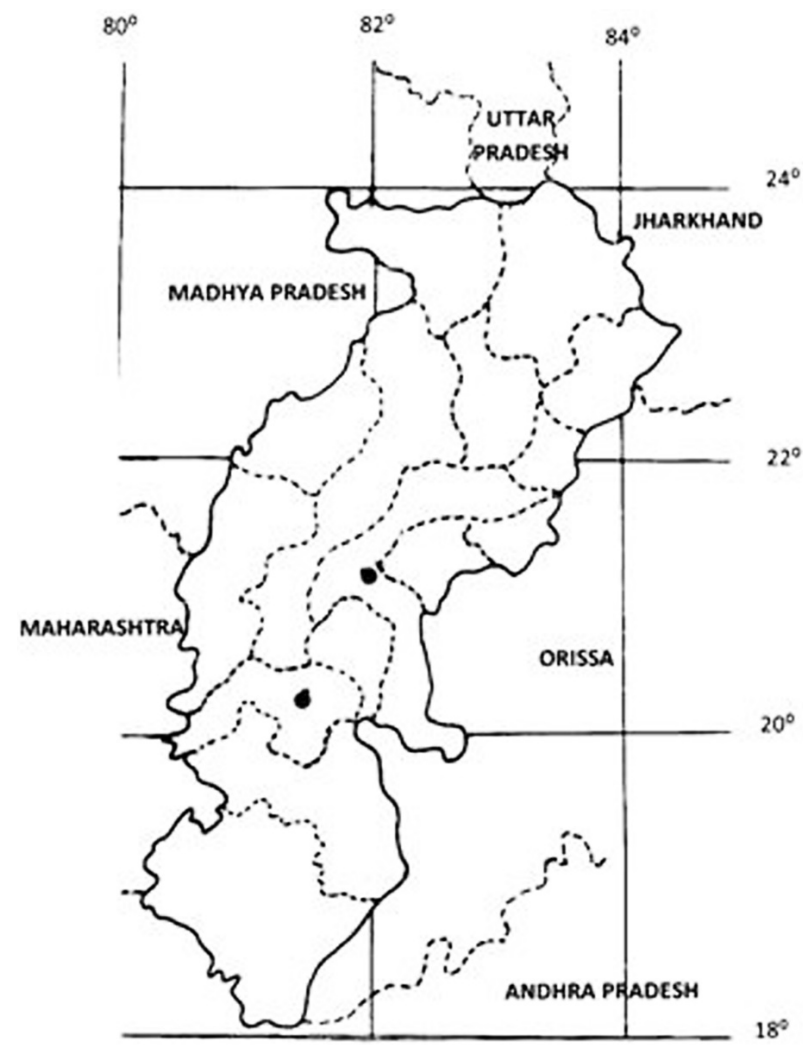

Figure 1. Map of Chhattisgarh showing collection spots

strigosazonata (Schwein.) P.H.B. Talbot, but in latter the hymenophore is smooth. Conspicuously encrusted cystidia and septate hyphae with or without clamps are important characters of $A$. dregeanum.

This species was reported from Kanghwa Island, Kimpo Peninsula, South Korea (Lim et al. 2005) and StPetersburg, Russia (Zmitrovich et al. 2006).

Hjortstamia friesii (Lév.) Boidin \& Gilles Bull. Soc. mycol. Fr. 118(2): 99 (2003) [2002] (Fig. 3, Image 2)

\section{Material examined}

1.x.2008, on stored wood of Terminalia tomentosa W\&A., Gariabandh, Raipur, Chhattisgarh, 21014'1"N \& 81038'1"E, coll. C.K Tiwari, Jagrati Parihar \& R.K. Verma, Reg.no. TF 1141.

Thelephora friesii Lév. Syst. Verz.: 17 (1854)

Basidiome: annual, resupinate, non poroid, papery soft and pliable, ochraceous to brown, velvety to tomentose. Hymenophore: smooth to slightly wrinkled or occasionally folded, with shallow depressions, pale cinnamon brown. Xanthochroic reaction: all parts of the fruit body change the colour in $\mathrm{KOH}$ into violet. Context: more or less concolorous, with the hymenium and separated from the much looser and paler context by a distinct dark line which is most prominent in older parts of the basidiome. Hyphal system: dimitic, generative hyphae septate with or without
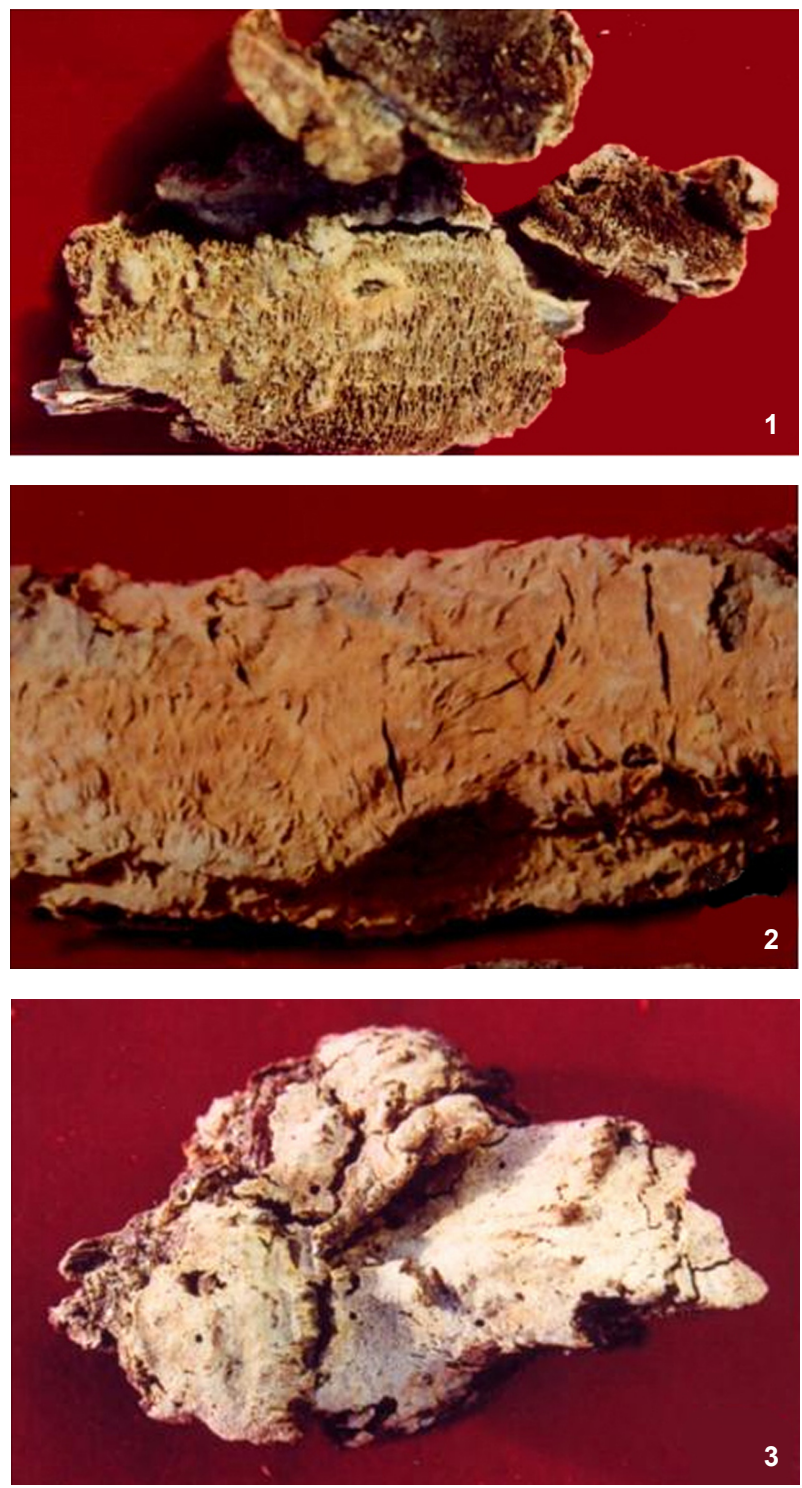

Images 1-3. Fruit bodies of resupinate wood decaying fungi. 1 - Australohydnum dregeanum; 2 - Hjortstamia friesii; 3 - Schizopora flavipora.

clamps, hyaline and thin-walled, 2.5-3 $\mu$ m wide, skeletal hyphae abundant in subhymenium and context, thickwalled, but with a distinct lumen, hyaline 4-5 $\mu$ m wide, amyloid. Cystidia: metuloids, heavily encrusted in apical region, hyaline, $17.5-22.5 \mu \mathrm{m}$ in diameter and $80 \mu \mathrm{m}$ from septum to apex. Basidia: clavate $18-30$ x 4-6 $\mu \mathrm{m}$, basally simple septate, no sterigmata seen. Basidiospores: ellipsoid to sub-cylindrical, hyaline, thin-walled, 4.5-7 $\mathrm{x}$ 2.5-3 $\mu \mathrm{m}$.

This fungus causes white fibrous rot.

The violet colour of the hymenophore on treatment with $\mathrm{KOH}$, and the coarsely encrusted, hyaline, cystidia are the characteristics of this species. Skeletocystidia are not present in this species.

The species was reported from tropical Asia, Pakistan, 

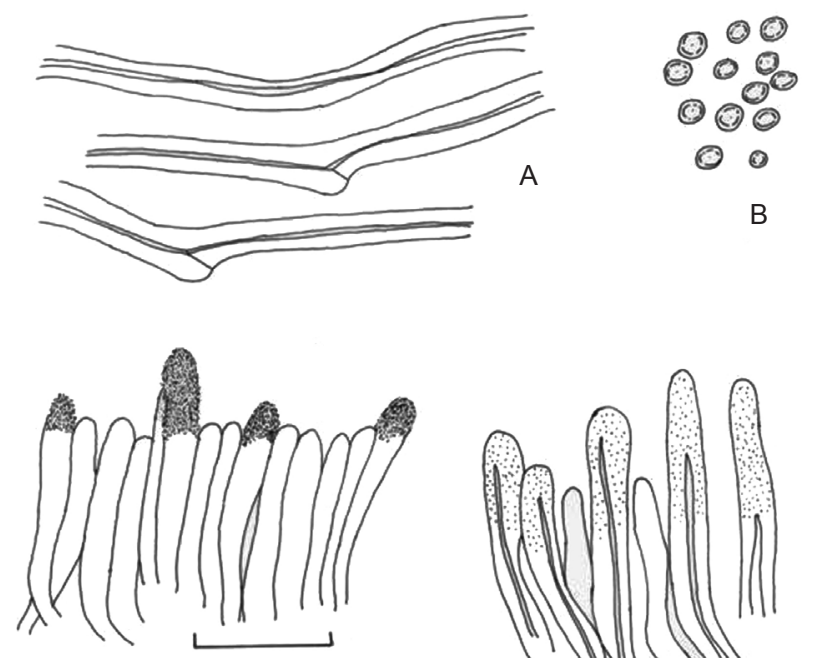

C

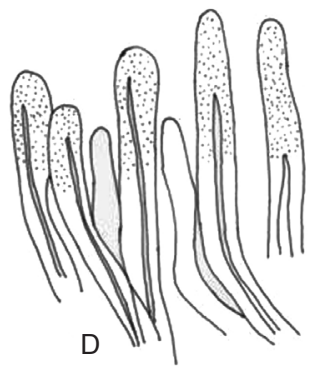

Figure 2. Australohydnum dregeanum (scale 20 $\mu \mathrm{m})$. A - generative hyphae; B - basidiospores; C - hymenium with basidia and lamprocystidia; D - fascicles of cystidia.

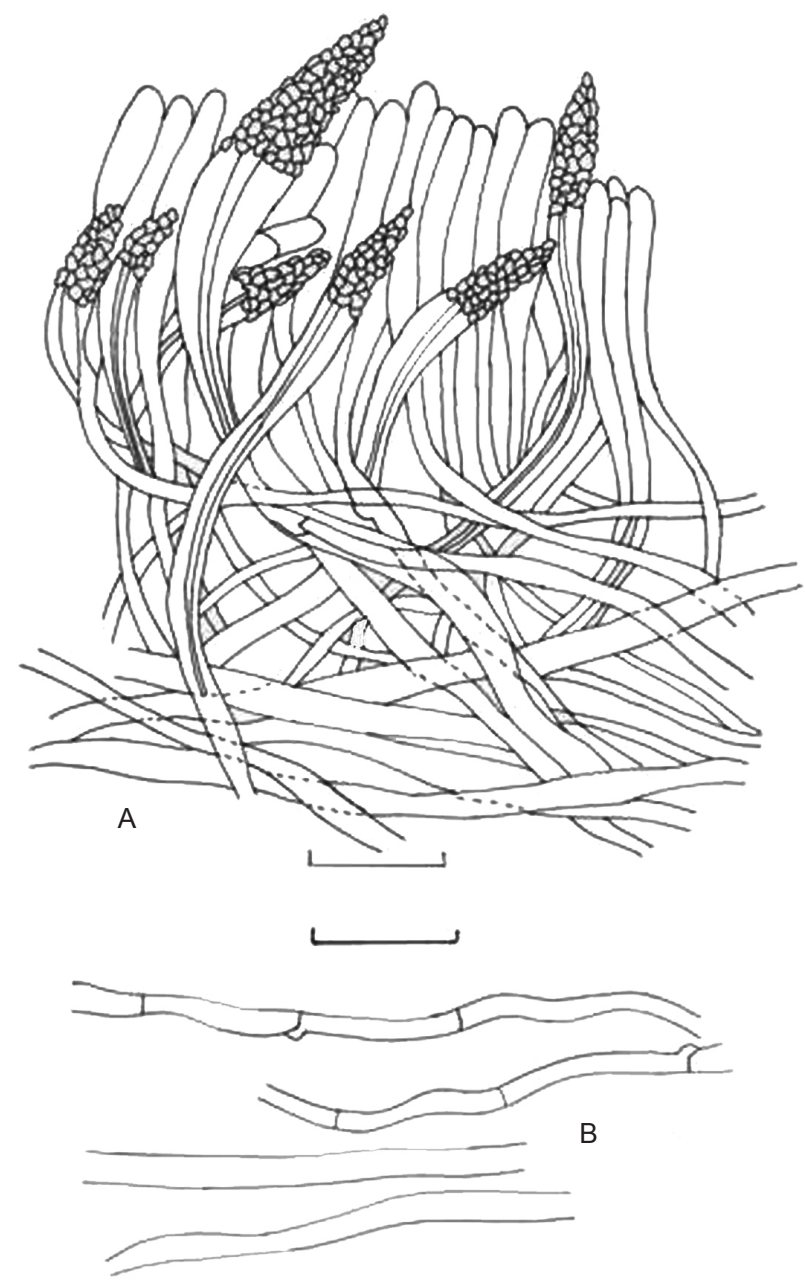

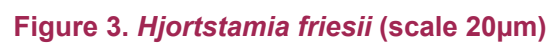

A - hymenium with cystidia, basidia; B - generative and skeletal hyphae.
China and New Guinea (Hjortstam \& Ryvarden 1990).

Schizopora flavipora (Berk. \& M.A. Curtis ex Cooke) Ryvarden, Mycotaxon 23: 186 (1985) (Fig. 4, Image 3)

\section{Material examined}

30.ix.2008, on dead hard wood of Lannea coromandelica (Houtt) Mett, Gariabandh, Raipur, Chhattisgarh, 21014'1'N \& 81038'1"E, coll. C.K Tiwari, Jagrati Parihar \& R.K. Verma, Reg.no. TF 1142.

Poria flavipora Berk. \& M.A. Curtis ex Cooke Grevillea 15(73): 25 (1886).

Basidiome: annual, resupinate, coriaceous to tough, fibrous. Xanthochroic reaction: all parts of fruit body turn brown. Hymenophore: poroid, white to cream when dry, appressed, pores 4-5 per mm, margin thin. Context: 1-1.5 $\mathrm{mm}$ thick, cream coloured. Hyphal system: monomitic, generative hyphae with clamps, hyaline, thin- to thickwalled, 3-4 $\mu \mathrm{m}$ wide, amyloid. Cystidia: present but more like encrusted hyphoids. Basidia: clavate, with four sterigmata, 5-12 × 3-5 $\mu \mathrm{m}$, with a basal clamp. Basidiospores: not seen.

This fungus causes white fibrous rot.

Earlier reports derive from deciduous trees (Quercus forests) from Korea (Lim \& Jung 2001) and on coffee tree as Poria hypolateritia Berk. ex Cooke from Sri Lanka (Petch 1916).
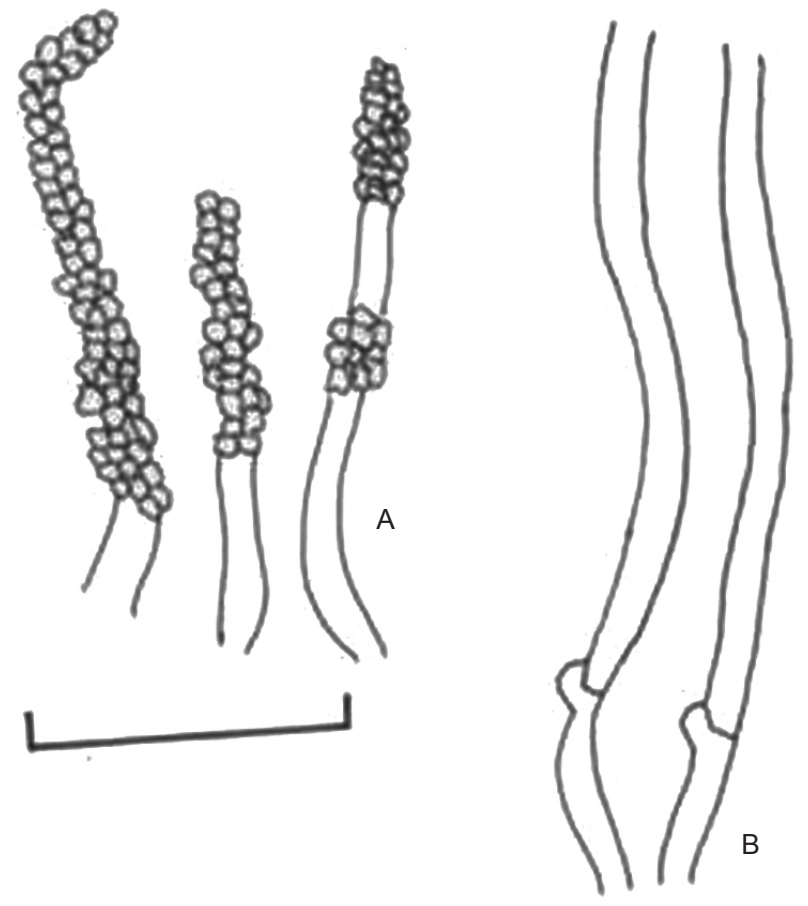

Figure 4. Schizopora flavipora (scale $20 \mu \mathrm{m}$ ) A - cystidia; B - generative hyphae 


\section{REFERENCES}

Bagchee, K. \& B.K. Bakshi (1951). Poria monticola Murr. on chir (Pinus longifolia Roxb.) in India. Nature (London) 167 4255.

Bakshi, B.K. (1971). Indian Polyporaceae (on tree and timber). Indian Council of Agriculture Research, New Delhi, 246pp.

Banerjee, S.N. (1947). Fungal flora of Calcutta and suburbs.1. Bulletin of Botanical Society of Bengal 1: 37-54

Bhide, V.P., A. Pandey, A.V. Sathe, V.G. Rao \& P.G. Patwardhan (1987). Fungi of Maharashtra. Supplement-I. Maharashtra Association for the Cultivation of Science, Research Institute, Pune, 146pp.

Bilgrami, K.S., Jamaluddin \& M.A. Rizawi (1979). Fungi of India-I. List and References. Today's and Tomorrow's Printers and Publisher, New Delhi, 467pp.

Bilgrami, K.S., Jamaluddin \& M.A. Rizawi (1981). Fungi of India-II. Host Index and Addenda. Today's and Tomorrow's Printers and Publisher, New Delhi, 128pp.

Bilgrami, K.S., Jamaluddin \& M.A. Rizawi (1991). Fungi of India. List and References Today's and Tomorrow's Printers and Publisher, New Delhi, 798pp.

Bose, S.R. (1938). Polyporaceae of Bengal X. Bulletin of Carmichael Medical College 11: 1-18.

Burdsall, H.H. (1985). A contribution to the taxonomy of the genus Phanerochaete (Corticiaceae, Aphyllophorales). Mycologia Memorial 10: 166.

Butler, E.J. \& G.R. Bisby (1954). Fungi of India (Revised by R.S. Vasudeva). Indian Agricultural Research Institute, New Delhi, 552pp.

Dai, Y.C. (2000). A checklist of polypores from Northeast China Karstenia 40: 23-29.

Donk, M.A. (1962). Notes on resupinate Hymenomycetes. IV Persoonia 2: 217-238.

Gilbertson, R.L. \& L. Ryvarden (1987). North American Polypores 1-2. Fungiflora, Oslo, 437-885pp.

Hattori, T. \& S. Lee (1999). Two new species of Perenniporia described from a lowland rain forest of Malaysia. Mycologia 91: 525-531.

Hjortstam, K. \& L. Ryvarden (1982). Aphyllophorales from Northern Thailand. Nordic Journal of Botany 2: 273-281.

Hjortstam K. \& L. Ryvarden (1990). Lopharia \& Porostereum (Corticiaceae). Synopsis Fungorum 4: 1-68.

Jamaluddin, M.G. Goswamy \& B.M. Ojha (2004). Fungi of India 1989-2001. Scientific Publisher, Jodhpur 326pp.

Jülich, W. (1976). Studies on resupinate Basiodiomycetes IV. Persoonia 8: 431-442.

Lee S.J., C. Kim, J.Y. Park, K.R.U. Mo Kim, Y.G. Yoon \& H.S. Jung (2004). Unrecorded Higher Fungi of the Songhisan National Park. Mycobiology 32(2): 68-73.
Lim, Y.W. \& H.S. Jung (2001). Taxonomic study of Korean Schizopora. Mycobiology 29(4): 194-197.

Lim, Y.W., H.Y. Kim \& H.S. Jung (2001). The Aphyllophorales of Mungyong Saejae. Mycobiology 28(3): 142-148.

Lim, Y.W., J.S. Lee, H.Y. Kim \& H.S. Jung (2005). Wood rotting fungal flora of Kanghwa Island. Mycobiology 33(4): 167172.

Natarajan, K. \& K. Kolandavelu (1998). Resupinate Aphyllophorales of Tamil Nadu, India. Centre for advanced study in Botany, University of Madras, 133pp.

Parmasto, E. (1986). Preliminary list of Vietnamese Aphyllophorales and Polyporaceae s. str. Scripta Mycoligia 14: 1-88.

Petch, T. (1916). A preliminary list of Ceylong Polypori. Annual Report of Botanical Garden Paredeniya 6: 1-58.

Rattan, S.S. (1977). The Resupinate Aphyllophorales of the North Western Himalayas. J. Cramer, In der A.R. K.G. FL9490 Vaduz, Germany, 427pp.

Roy, A. \& A.B. DE (1996). Polyporaceae of India. International Book Distributors, Dehradun, 309p.

Ryvarden, L. \& J. Johansen (1980). A preliminary Polypore Flora of East Africa, Fungiflora. Oslo, Norway, 636pp.

Ryvarden, L. \& R.L. Gilbertson (1994). European Polypores 2. Synopsis Fungorum 7: 394-743.

Saksena, S.B. \& K.M. Vyas (1964). The wood-decaying fungi of Sagar, Madhya Bharat. Journal of University of Sagar 1113(B) 15-28.

Sarbhoy, A.K., J.L. Vashney \& D.K. Agarwal (1986). Fungi of India (1977-81). Associate Publishing Company, New Delhi, 274pp.

Sarbhoy, A.K., J.L. Vashney \& D.K. Agarwal (1996). Fungi of India (1982-92). CBS Publisher \& Distributer, New Delhi 350pp.

Sarbhoy, A.K., G. Lal \& J.L. Vashney (1975). Fungi of India (Revised) 1967-71. Navyug Traders Bookseller \& Publisher, New Delhi, 148pp.

Tandon, R.N. \& Sudhir Chandra (1964). Supplement to the List of Indian Fungi (1957-1962). Bishen Singh, Mahendra Pal Singh and Periodical experts Dehradun, India, 246pp.

Thind, K.S. \& R.S. Dhanda (1980). The Hydnaceae of North West Himalayas-II. Indian Phytopathology 28: 57-65.

Verma, R.K., N. Sharma, K.K. Soni \& Jamaluddin (2008). Forest Fungi of Central India. International Book Distributing Company, Lucknow, India, 418pp.

Zmitrovich, I.V., V.F. Malysheva \& A.S. Wjacheslav (2006). A new morphological arrangement of the Polyporales. I. Phanerochaetineae. Mycena 6: 4-56. 